\title{
The Improvement of Degradation Strength of aAlkyd Resin EZ 528 Used in Rotating Machines
}

\author{
TRAIAN ZAHARESCU, EDUARD-MARIUS LUNGULESCU*, ALINA DUMITRU, \\ VIRGIL MARINESCU \\ National R\&D Institute for Electrical Engineering ICPE-CA 313, Splaiul Unirii, 030138, Bucharest, Romania
}

\begin{abstract}
The addition of inorganic phase consisting of Ce-doped PbZrO3, a promising solution to increase the thermal and radiation strengths of electroinsulating alkyd resin EZ 528 used in rotating machines is studied. The delay of oxidation of filler is based on the electronic interaction between the former degradation intermediates and lattice defects.
\end{abstract}

Keywords: alkyd resin, stability improvement, doped lead zirconate, radiation ageing

\section{Introduction}

The durability of any organic material depends on its stability strength against degradation. The main factors that influence the product life time are related to the material structure and the consistency as well as the presence of protecting formulation component diminishing the aging rate of substrate and extend the oxidation induction time. There are several alternatives through which the oxidation process of organic compounds can be efficiently delayed: the increase in the crosslinking degree [1,2], the addition of various classes of antioxidants [3-7], the loading with proper structures like nanoparticles [8-10], inorganic complexes [11], blending component [12, 13].

Because the oxidation degradation of organic material: polymers, lacquers, vanishes, resins, paints, occurs by the formation of peroxyl radicals as the propagation intermediates during the self-catalytic process, the blocking of primary step consisting the reactions between free radicals and diffused molecular oxygen is mandatory. A new procedure applicable for the increase of oxidation induction periods is the inclusion of doped inorganic compounds $[14,15]$. The lattice defects appeared by the presence of doping atom makes possible the scavenging of free radicals, the moieties with unpaired electrons, in the existing traps. The caught radicals become unavailable for oxidation and the degradation process is consequently delayed.

As it was previously proved in the cases of polymers $[16,17]$, cerium showed the most relevant efficiency in the protection against oxidation. The extension of this activity over other classes of organic structures like electroinsulating resins represent a reliable solution for the extension of operation life time and an easy applicable procedure for material quality improvement. The addition of this kind of filler could be recommended for the manufacture of rotating devices as well as the large applications in building erection because the interaction between the insulation sheets (sealants, electrical cables, window frames,) and construction materials does not affect the life time of polymer products.

The purpose of this study is the identification of optimal conditions for the amelioration of oxidation strength of EZ 528 alkyd resin used for the impregnation of rotors in microelectrical devices. The new proposed procedure for attaining high thermal durability represents a novel direction in the improvement of functional features of organic electrical insulators. The engineering effect of this type of inorganic filler is described by the delay of ageing under various energetic conditions, which cause the diminution of material life time.

\footnotetext{
*email: marius.lungulescu@icpe-ca.ro
} 
Though the oxidative degradation mechanism of alkyd resins is essentially based on the scission of $\mathrm{C}-\mathrm{O}$ bonds [17] and the majority of radicals are oxygen centered configurations, the presence of natural and induced defects acting as traps in the doped inorganic lattice $\left(\mathrm{ZrPbO}_{3}\right)$ allows the inactivation of former intermediates against their reactions with oxygen. The stabilization effect of doped inorganic phase is based on the energetic considerations, namely the difference that exists between the conduction bands of dopant and lattice [18]. The accelerated degradation initiated by $\gamma$ exposure can be efficiently inhibited by this kind of stabilization system, which has proved the reliable alternative for the improvement of operation quality of polymers [16].

\section{Materials and methods}

The inorganic phase added in the synthesized formulations contains (1-x) $\mathrm{PbZrO} 3$ and $\mathrm{x}$ doping atoms, in our case $-\mathrm{Ce}$, where $\mathrm{x}=0.01$. The dopant was added as $\mathrm{CeO}_{2}$. All reagents are of $\mathrm{p}$. a. grades provided by Merck Co. The stabilizing powder was obtained by solid state reaction technique in two steps. In the first step the PbZrO3 powder was obtained. The technology applied to this powder has been described elsewhere [14].

In the second step the ceramic powder was prepared from stoichiometric mixtures of $\mathrm{PbZrO}_{3}$ powder and doping oxide $\left(\mathrm{CeO}_{2}\right)$. The technology of obtaining ceramic powder was carried out using 3 steps of milling and 2 steps of sintering. The powders were homogenized in a planetary mill (Fritsch mill) for $6 \mathrm{~h}$. The resulting mixture was dried in an electrical oven at $80{ }^{\circ} \mathrm{C}$, calcined at $800{ }^{\circ} \mathrm{C}$ for $4 \mathrm{~h}$ and then re-milled for $10 \mathrm{~h}$ and re-calcined at $1120^{\circ} \mathrm{C}$ for $2 \mathrm{~h}$. After the second calcination the mixture was milling again for $10 \mathrm{~h}$, then dried and sieved. The ceramic powder thus obtained was further used for the further stage of hybrid preparation.

The samples were obtained by the solvent evaporation from EZ 528 alkyd resin, where $1 \%$ wt filler is present, except control (the resin free of zirconate powder). The wet samples placed in aluminum pans were placed in an electrical oven at $150{ }^{\circ} \mathrm{C}$ for $1.5 \mathrm{~h}$. During this time the materials were cured.

For the accelerated degradation the $\gamma$-processing was achieved in an irradiation machine Ob-Servo Sanguis, (Hungary) at $50 \mathrm{kGy}$ (Dose rate: $0.9 \mathrm{kGy} / \mathrm{h}$ ). The samples were analyzed soon after the elapsing irradiation period.

The radiation thermoluminescence spectrum that represents the glow curve of the inorganic component irradiated at $50 \mathrm{kGy}$ was recorded on TLM equipment produced by Fimel (France) using the following conditions: temperature range: $35-450{ }^{\circ} \mathrm{C}$; heating rate: $2{ }^{\circ} \mathrm{C} / \mathrm{s}$ and $\mathrm{PM}$ voltage: $850 \mathrm{~V}$.

The oxidation resistance was evaluated by chemiluminescence (CL) measurements, either by isothermal heating at $110{ }^{\circ} \mathrm{C}$ or by nonisothermal investigations at four heating rates $(3.7,5.0,10.0$ and $15.0{ }^{\circ} \mathrm{C} \mathrm{min}{ }^{-1}$ ). From these results activation energies for the degradation of EZ 528 resin and hybrid material containing $\mathrm{Ce}$ doped $\mathrm{ZrPbO}_{3}$ were calculated.

\section{Results and discussions}

The powder phase that is added to the EZ 528 alkyd resin presents several defects by which it acts as the stabilizer against oxidation [16]. The inorganic blending component of EZ 528 resin hybrids has various trapping points where free radicals are scavenged and blocked against their reactions with oxygen molecules. As it can be expected, the concentration of filler is one of the most important factor that states the stabilization level effect [14]. The increase in the filler loading enhances the probability of scavenging. It awas proved that the blocking action on radical reactivity is proportional with the concentration of traps and, consequently with the amount of doped filler. The most active trap corresponds to the radio thermoluminescence (RTL) photon emission occurred at $150{ }^{\circ} \mathrm{C}$ (Figure 1). The glow curve recorded on irradiated Ce-doped lead zirconate shows an emission maximum at 142 ${ }^{\circ} \mathrm{C}$. This temperature is far from room temperature that demonstrates a good stability of trap distribution along the handling period. The favorable value of this temperature tells us the possibility of activity at moderate high temperatures and the defects are not recombined outside the stabilization 
process. The second peak placed at $395{ }^{\circ} \mathrm{C}$ can be considered as a dosimetric shoulder. The traps that are recombined for this emission are very stable and they may be considered as the main way through which the free radicals generated by the degradation of alkyd resin are blocked against oxidation.

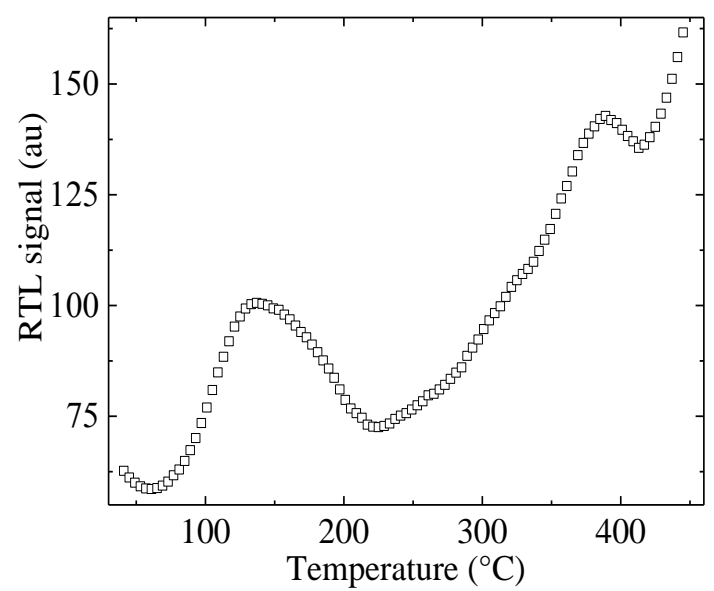

Figure 1. Glow curve recorded on $\mathrm{Ce}$ doped $\mathrm{PbZrO}_{3}$ powder irradiated at $50 \mathrm{kGy}$

The efficiency of oxidation blocking activity depends intrinsically by the electron surrounding of doping atoms. Consequently, the development of degradation occurs specifically in relation with the type of chemical features of dopant atoms, because the trapping effects depend strongly on the electronic density of host lattice and the electronic distribution of dopant, as well. The stabilization action follows the filler concentration profile. Unfortunately, the interaction between the lattice traps and available free radicals takes plase on the material surface. As it happens with all superficial processes occurred at higher concentration, the asimpthotic dependence of the foreseen effect on concentation would be obtained. Accordingly, the most relevant results are obtained, when the reactive spots are placed at a certain distances from each other analogous with the space spreading of traps. The increase in the filler concentration has not only a screening effect, but also a significant modification in the homogeneity of particle distribution.

In Figure 2 the existence of active traps in doped $\mathrm{ZrPbO}_{3}$ filler is proved by the great difference between the emission intensities at the main emission peak. Complementary, the influence of this peculiarity revealed by the degradation of organic substrate can be exemplified for the nonisothermal chemiluminescence determinations of hybrid EZ 528 alkyd resin. The photoemission intensity in the case of oxidation for the compounded resin is twice smaller than the pristine emitter.

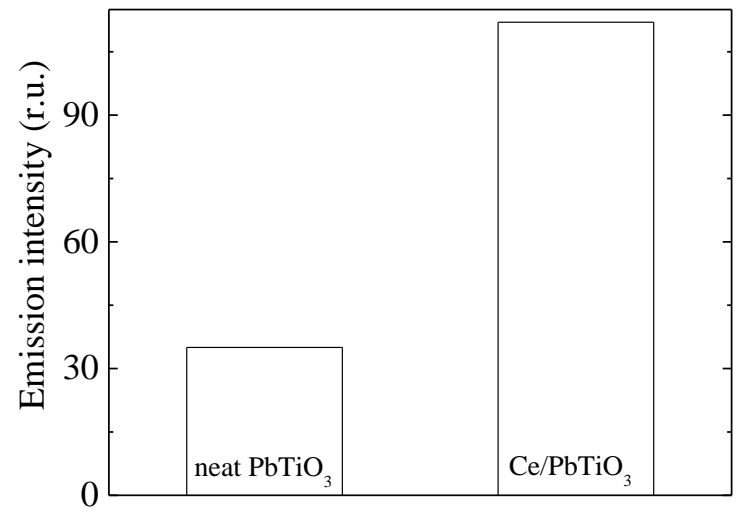

Figure 2. The CL emission intensities measured by radiation thermoluminescence at $142{ }^{\circ} \mathrm{C}$ 
During the $\gamma$-processing of alkyd resin/doped $\mathrm{ZrPbO}_{3}$ compounds, when host polymer is degraded by molecular scissions, the oxidation initiators can normally follow their reactions with diffused oxygen, as it is happened in the operation periods or they are trapped in the existing defects on the particle surface [8]. The intermediates that present unpaired electrons will be bonded on the particle surface by an electric interaction between solid state defects and the body of intermediates.

The contribution of doping component to the thermal behavior of basic alkyd resin is determined by the electronic configurations of doping atoms and by the electronic interaction between free charge carries, namely radicals appeared after the molecular scission in organic phase, as well. The exposure of hybrid compound based on alkyd resin modifies in a certain extent the influence of filler presence on the level of oxidation delaying [14]. The concentration of radicals in the neighborhood of defects imposes specific sequence of doping atoms in respect with the trap depths.

For the depicting the stabilization effect of inorganic doped component, the example of Cerium is relevant. As it can be noticed from Figure 3 the degraded substrate presents abundant amounts of radicals that are converted into peroxyl radicals during the initiation step of self-catalytic process of oxidation. The maximum of chemiluminescence intensity shown between $155^{\circ} \mathrm{C}$ and $175^{\circ} \mathrm{C}$ which can be ascribed to the conversion of peroxyl radical into carbonyl intermediates is most evident for the action of filler, where the desorption of trapped radicals allows the photoemission. The further increase in the environmental temperature determines an acceleration of oxidation in organic bulk because of the fast increase in the local concentration of oxidable radicals [17]. The degradation mechanism of alkyd resin was previously reported [18]. The free radicals generated by the molecular scissions during the ageing of resin joint partially the inorganic surface and are efficiently removed from the organic system.
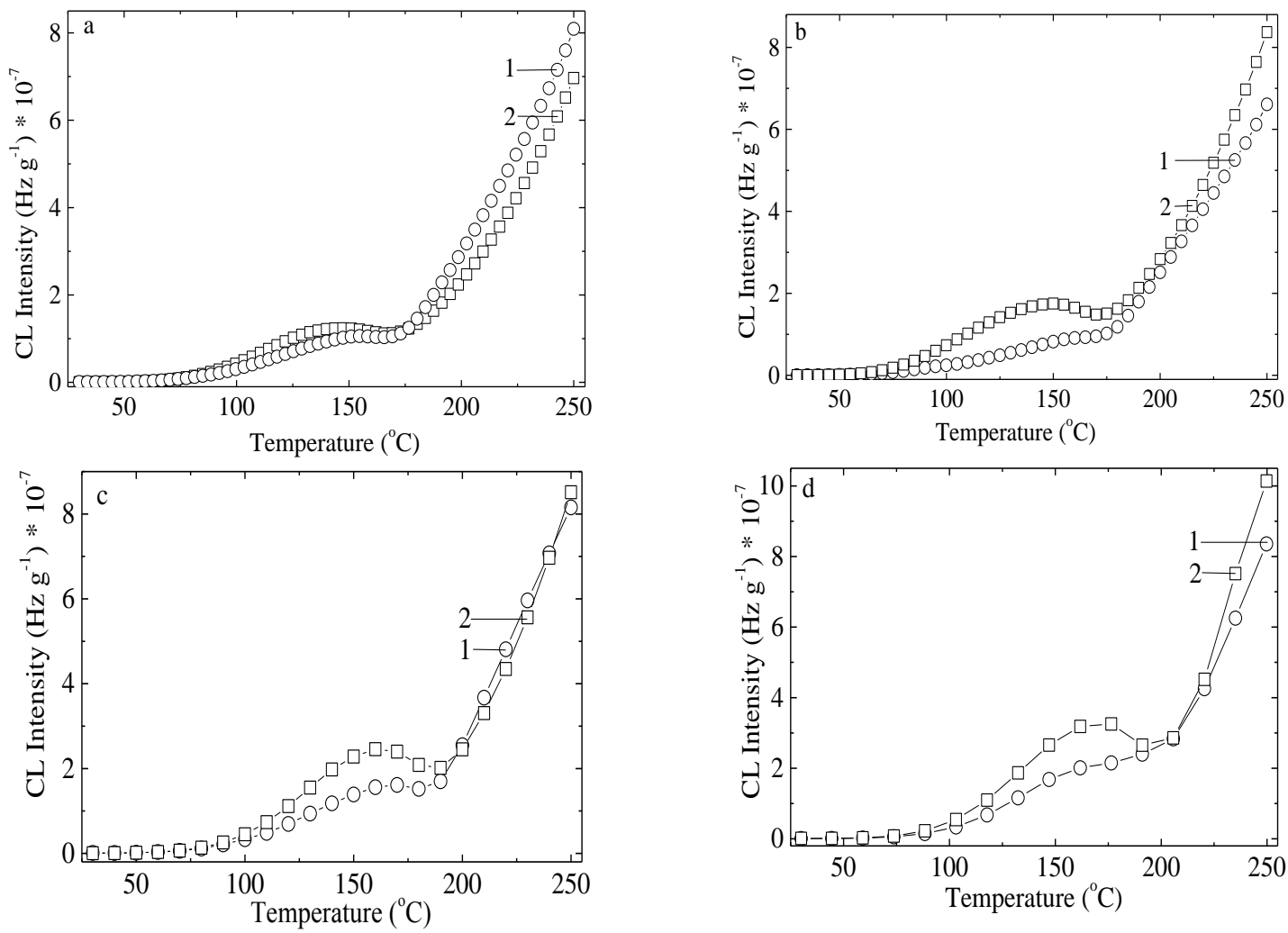

Figure 3. Nonisothermal CL spectra recorded on neat (1) and Ce-doped $\mathrm{ZrPbO}_{3}$ (2) alkyd resin. Heating rates: (a) $3.7^{\circ} \mathrm{C} \mathrm{min}^{-1}$, (b) $5{ }^{\circ} \mathrm{C} \min ^{-1}$, (c) $10{ }^{\circ} \mathrm{C} \min ^{-1}$, (d) $15^{\circ} \mathrm{C} \mathrm{min}-1$

In Figure 4, the SEM images recorded on two different oxidation stages of resin modified with Cedoped $\mathrm{ZrPbO}_{3}$ illustrate the contribution of inorganic phase on the curing of resin [19]. The consequence of desorption in the evolution of material microstructure is the curing of resin, which is 
possible only after the removing scavenged radicals on the defect positions existing on the surface of inorganic particles

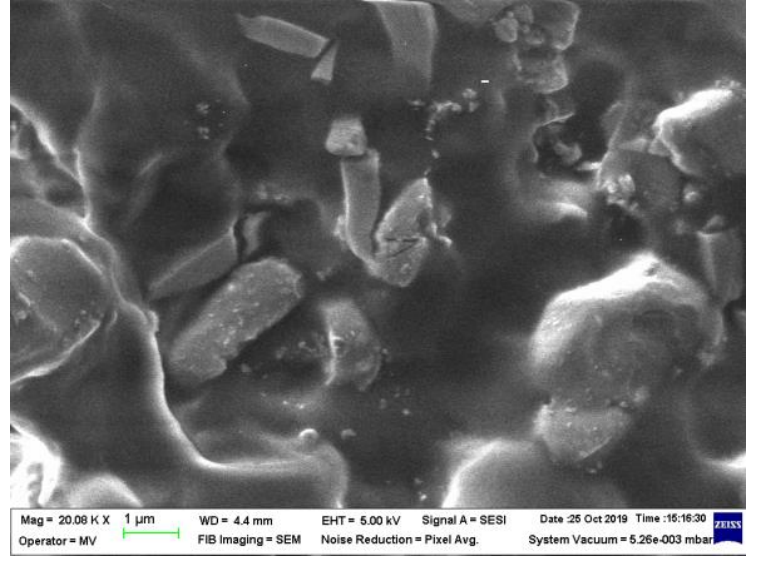

(a)

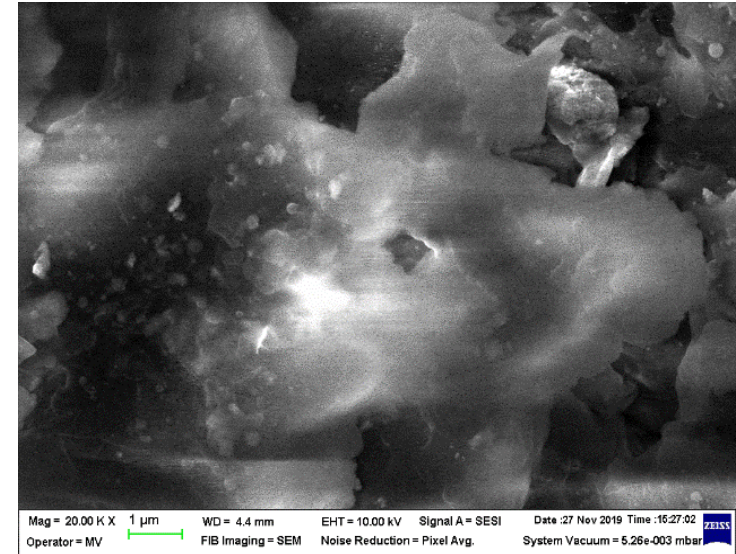

(b)

Figure 4. SEM images on the pristine (a) and $50 \mathrm{kGy}$ irradiated alkyd resin containing Ce-doped $\mathrm{ZrPbO}_{3}$ (b)

The reduction of oxidation rate and the efficient activity of doped filler in respect with the progress of degradation can be remarked in Figure 5. In spite of the degradation mechanism that is described by the scission of $\mathrm{C}-\mathrm{O}$ bonds and the generation of oxygen centered radicals, the electronegativity of radical affinities offers the possibility of inactivation of radicals against their oxidation reactions. The dopant like cerium atoms creates the opportunity for scavenging reactive entities whose abundancy would accelerate material ageing. The diminution of radical concentration due to their adsorption on the particle outer surface hinders the propagation of degradation. The differences that exist between the studied hybrid compositions based on alkyd resin EZ 528 have showed that radical configurations containing doped $\mathrm{ZrPbO}_{3}$ powders are reliably explained by the contribution of superficial defects that interact with the intermediates born during thermal and radiochemical degradation. The energetic conditions that are satisfied by the structural configuration of inorganic lattices determine the increase in the durability of resin, if the antioxidant features of solid components are enough adapted to the catching radical intermediates.
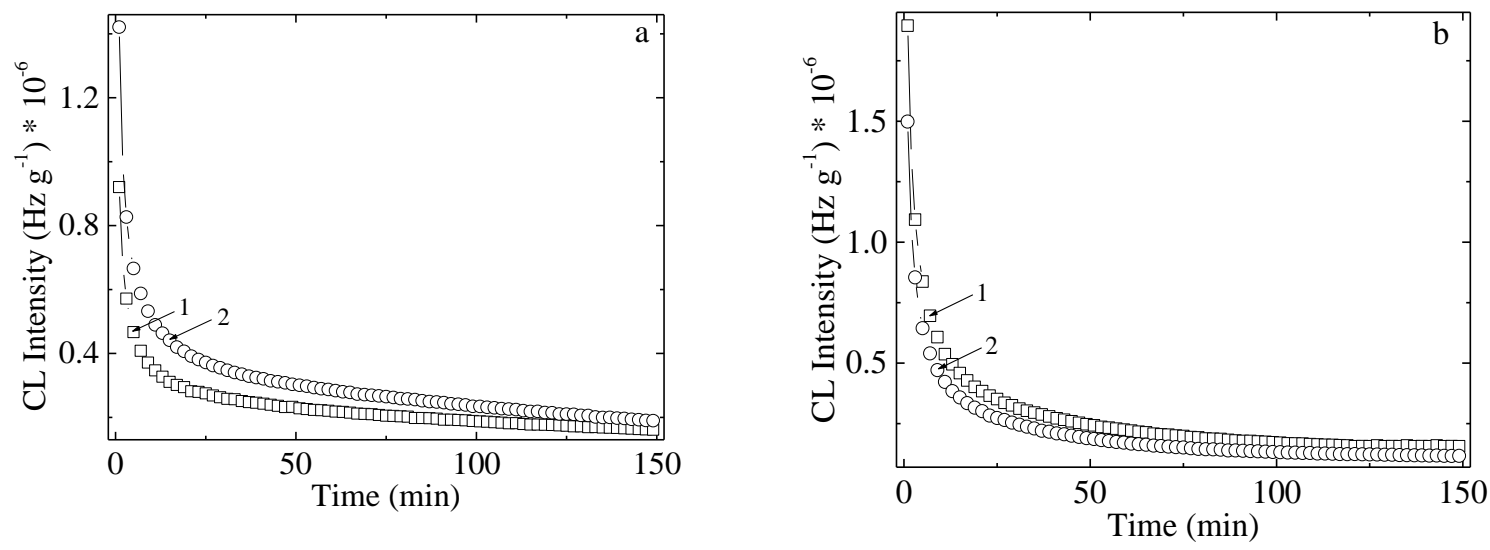

Figure 5. Isothermal CL spectra recorded on neat (1) and Ce-doped $\mathrm{ZrPbO}_{3}$ (2) alkyd resin. Irradiation doses: (a) $0 \mathrm{kGy}$, (b) $50 \mathrm{kGy}$. Heating temperature: $110{ }^{\circ} \mathrm{C}$

The energetic requirements for the promotion of stability improvement are illustrate by the activation energy involved in the delaying oxidation of alkyd resin substrate (Tables 1 and 2). 
Table 1. Onset oxidation temperatures determined by nonisothermal CL measurements

\begin{tabular}{|c|c|c|c|c|c|}
\hline \multirow{2}{*}{ ple } & \multirow{2}{*}{$\begin{array}{l}\text { Dose } \\
\text { (kGy) }\end{array}$} & \multicolumn{4}{|c|}{ Onset oxidation temperature $\left({ }^{\circ} \mathbf{C}\right)$} \\
\hline & & $3.7^{\circ} \mathrm{C} \mathrm{min}^{-1}$ & $5^{\circ} \mathrm{C} \min ^{-1}$ & $10^{\circ} \mathrm{C} \mathrm{min}^{-1}$ & $15^{\circ} \mathrm{C} \mathrm{min}^{-1}$ \\
\hline \multirow[t]{2}{*}{ nea } & 0 & 169 & 175 & 185 & 197 \\
\hline & 50 & 170 & 172 & 188 & 200 \\
\hline \multirow[b]{2}{*}{$\mathrm{d}$} & 0 & 178 & 183 & 190 & 201 \\
\hline & 50 & 177 & 182 & 193 & 200 \\
\hline
\end{tabular}

Table 2. Activation energies determined by nonisothermal CL measurements

\begin{tabular}{|c|c|c|c|}
\hline Resin sample & $\begin{array}{c}\text { Dose } \\
(\mathbf{k G y})\end{array}$ & $\begin{array}{c}\text { Activation energy, } \mathbf{E}_{\mathbf{a}} \\
\left(\mathbf{k J ~ m o l} \mathbf{~}^{\mathbf{1}}\right)\end{array}$ & $\mathbf{R}^{\mathbf{2}}$ \\
\hline \multirow{2}{*}{ neat } & 0 & 85.38 & 0.98962 \\
\hline \multirow{2}{*}{ hybrid } & 50 & 82.30 & 0.99390 \\
\cline { 2 - 4 } & 0 & 110.07 & 0.99125 \\
\cline { 2 - 4 } & 50 & 100.68 & 0.99991 \\
\hline
\end{tabular}

These values prove the involvement of inorganic component of samples by the screening oxidation ageing by the attachment of radicals. The evident effect of protection activity of Ce-doped lead zirconate is the delay of ageing in the favor of recombination through which the gelation occurs. This contribution was already reported for other type of materials, which are subjected to an accelerated process of degradation [20,21].

The scavenging activity exhibited by lead zirconate in the inactivation of degradation intermediates of alkyd resin is functionally similar with the contribution brought about by silver in photodegradation of $\left\{2-\left[(2,6\right.\right.$-dichloropfenyl)amino]phenyl $\}$ acetic acid catalyzed by $\mathrm{Ag}$-doped $\mathrm{TiO}_{2}$ [22] and with the behavior of carbonic materials during their operation periods [23].

The previous XRD investigations on the modification of microstructure of doped zirconate fillers [16] demonstrated that small variation of signal would be recorded when the lattice paramenetrs remain constant. Consequently, the morphological aspects in relation with the distribultin of traps do not require a special attention. As it was demonstated that the most determinative factors influencing the stabilization activity of doped zirconate are the volum amount of traps and their distribution in the support lattice.

\section{Conclusions}

The presence of doped inorganic component of $\mathrm{PbZrO}_{3}$ in alkyd resin causes an increase in the stability of organic material. The interaction between the two types of compounds belonging to different classes of molecular structures consists of the scavenging of radicals generated in the alkyd resin and their slow desorption from particle surface feeding either curing or oxidation. The accelerated degradation induced by the $\square$-exposure of samples is efficiently delayed and the higher activation energies required for this oxidation ageing are relevant for the direct involvement of traps existing on the inorganic particle surface. The rates of thermal degradation that characterize the resistance of Ce-doped $\mathrm{PbZrO}_{3} /$ alkyd resin systems are influenced by the presence of material defects which controls the scavenging free radicals. The progress in the accumulation of oxidation products described by the modification of chemiluminescence photonic emission is illustrated by the presence of a characteristic peak in the nonisothermal measurements. The improvement in the material durability is depicted by evolution of oxidation states evaluated on different degradation stages in isothermal chemiluminescence investigation.

Acknowledgements: The financial support was provided by Ministry of Research and Innovation, through PN 19310101-46N/2019, contract 30PFE/2018 (between National R\&D Institute for Electrical Engineering ICPE-CA and Romanian Ministry of Research and Innovation - MCI) and the contract 3PS/28.08.2019 


\section{References}

1. LIU, Q., WU, J., TAN, T., ZHANG, D., TIAN, W., Preparation, properties and cytotoxicity evaluation of a biodegradable polyester elastomer composite. Polym. Degrad. Stab., 94 (9), 2009, $1427-1435$.

2. ZHAO, Y., WEN, J., GE, Y., ZHANG, X., GONG, Y., Fabrication of stable biomimetic coating on PDMS surface: Cooperativity of multivalent interactions. Appl. Surf. Sci., 469, 2019, 720-730.

3. KIRSCHWENG, B., TÁTRAALJAI, D., FÖLDES, E., PUKÁNSZKI, B., Natural antioxidants as stabilizers for polymers. Polym. Degrad. Stab., 145, 2017, 25-40.

4. LI, R., SHI, K., YE, L., LI, G., Polyamide 6/graphene oxide-g-hindered phenol antioxidant nanocomposites: Intercalation structure and synergistic thermal oxidative stabilization effect. Compos. Part B-Eng., 162, 2019, 11-20.

5. NGUYEN, Q.H., PHAN, D. T., DANG, V. P., LE, A. Q., TRAN, T. H., Gamma Co-60 ray irradiation synthesis of dextran stabilized selenium nanoparticles and their antioxidant activity. Mater. Chem. Phys., 205, 2018, 29-34.

6. JIPA, S., ZAHARESCU, T., KAPPEL, W., DUMITRESCU, C., MARIŞ, M., MANTSCH, A., LUNGULESCU, M. Scavenger capacity of natural phenolics in some selected labiatae herbs. Optoelectron. Adv. Mat. - Rapid Comm., 2 (10), 2008, 669-673.

7. ION, V.A., PARVUlESCU, O.C., VELCEA, D., POPA, O., AHMADI, M., Physico-chemical parameters and antioxidant activity of Romanian sea buckthorn berries. Rev.Chim., 70, no. 12, 2019, 4187-4193.

8. BLANCO, I., ABATE, L., BOTTINO, A., Synthesis and thermal properties of new dumbbellshaped isobutyl-substituted POSSs linked by aliphatic bridges. J. Therm. Anal. Calorim., 116 (1), 2015, 5-13.

9. LI, S., SHI, X., FANG, C., LIU, N., Effect of graphite and Ag-plated graphite nanoplatelets on the thermal properties of polypropylene nanocomposites: Experimental studies and modeling. Thermochim. Acta, 630, 2016, 11-20.

10. LUNGULESCU, M.E., ZAHARESCU, T., PODINA C., Thermal and radiation stability of polyolefins modified with silica nanoparticles. J. Optoelectron. Adv. M., 16 (5-6), 2014, 719-725.

11. ZAHARESCU, T., ILIEŞ, D-C., ROŞU, T., Thermal and spectroscopic analysis of stabilization effect of copper complexes in EPDM. J. Therm. Anal. Calorim., 123, 2016, 231-239.

12. TWIGG, C., FORD, K., SCOTT, PARENT J., Peroxide-initiated chemical modification of polyolefins: In search of a latent antioxidant. Polymer, 176, 2019, 293-299.

13. BELLAM, B.A., THERY, R.C., KHALID, M., WALVEKER R., Effect of electron beam irradiation on thermal and crystallization behavior of PP/EPDM blend. Radiat. Phys. Chem., 141, 2017, 179-189.

14. BURNEA, L.C., ZAHARESCU, T., DUMiTRU, A., PlEŞA, I., CIUPRINA, F., Radiation stability of polypropylene/lead zirconate composites. Radiat. Phys. Chem., 94, 2014, 156-160.

15. ZAHARESCU, T., DUMITRU, A., LUNGULESCU, M. E., VELCIU, G., EPDM composite membranes modified with cerium doped lead zirconate titanate. Radiat. Phys. Chem. 118, 2016, 133137.

16. ZAHARESCU, T., Stabilization effects of doped inorganic filler on EPDM for space and terrestrial applications. Mater. Chem. Phys., 234, 2019, 102-109.

17. MATISOVÁ-RYCHLÁ, L., RYCHLÝ, J., SLOVÁK, K., Effect of the polymer type and experimental parameters on chemiluminescence curves of selected materials. Polym. Degrad. Stab., 82 (2), 2003, 173-180.

18. CARAMiTU, A. R., BUMBAC, M., NICOLESCU, C. M., ZAHARESCU, T., Alkyd hybrid coatings for electrical rotating machines. J. Therm. Anal. Calorim., 134, 2018, 2017-2027.

19. FURETTA, C., Handbook of thermoluminescence, World Scientific, New Jersey, 2003

20. PlOEGER, R., SCALARONE, D., CHIANTORE, O., Thermal analytical study of the oxidative stability of artists' alkyd paints. Polym. Degrad. Stab., 94, 2009, 2036-2041. 
21. BERTRAN, X., CHOLLON, G., DENTZER, J., GADIOU, R., FOUQUET, S., DOURGAS, M-A., REBILLAT, F., Oxidation behavior at moderate temperature under dry and wet air of phenolic resinderived carbon. Thermochim. Acta, 649, 2017, 13-21.

22. IHOS M., BOGATU C., LAZAU C., MANEA F., PODE R., Pharmaceutically active compounds degradation using doped $\mathrm{TiO}_{2}$ functionalized zeolite photocatalyst. Rev. Chim., 69 (1), 2018, 34-37.

23. MIREA, R., IORDOC M., OPRINA G., RIMBU G., Processing of Iridium doped materials and experimental investigation of their hydrogen adsorption capacity. Rev. Chim., 69 (6), 2018, 1468-1472.

Manuscript received: 7.02.2020 